\title{
Cofinanciamento das Políticas Sociais no Contexto do Federalismo Brasileiro do Século XXI*
}

\author{
Co-financing of Social Policies in the Brazilian Federalism Context of the 21st Century
}

Evilasio Salvador *

\begin{abstract}
Resumo:
O arranjo federativo pós-Constituição de 1988 vem indicando a maior responsabilidade das unidades federativas e dos munícipios na execução das políticas sociais, ao mesmo tempo que se conferiu maior autonomia na arrecadação tributária. A partir dos anos 2000, as novas regulamentações das políticas sociais nas áreas de educação, saúde e assistência social vêm exigindo um maior esforço de recursos orçamentários dos estados, do Distrito Federal e dos municípios, sem a criação ou aporte de receitas fiscais adicionais. Nas políticas sociais, importantes mudanças legislativas marcam a primeira década do século XXI no Brasil, com implicações diretas no arranjo federativo e por consequência no cofinanciamento das políticas sociais. O objetivo principal do artigo é analisar o montante de recursos aplicados pela União, estados, DF e municípios nas funções orçamentárias: assistência social, saúde e educação, no período de 2002 a 2012, evidenciando o confinaciamento dessas políticas sociais; assim como o de identificar alguns obstáculos criados pelo ajuste fiscal em curso no país para a expansão do cofinanciamento das políticas sociais.
\end{abstract}

Palavras-chave: Confinanciamento; Federalismo; Políticas Sociais.

\begin{abstract}
:
The federal arrangement post Constitution comes indicating greater accountability of federal units and municipalities in the implementation of social policies at the same time as it gave greater autonomy in tax collection. From the 2000s, the new rules of social policies in education, health and social assistance has required a greater effort of budgetary resources of the states, the Federal District and municipalities, without the creation or injection of additional tax revenue. In social policies, important legislative changes mark the first decade of this century in Brazil with direct implications on federal arrangement and therefore the co-financing of social policies. The main objective of this article is to analyze the amount of funds invested by the federal government, states,
\end{abstract}

\footnotetext{
- Texto base da conferência proferida, em 08/04/2014, no II Simpósio Orçamento Público e Políticas Sociais na Universidade Estadual de Londrina (UEL). O autor agradece a Profa. Vera Suguihiro e o Prof. Valdir Anhucci. Registrase também os agradecimentos à Coordenação de Aperfeiçoamento de Pessoal de Nível Superior (CAPES) pela concessão da bolsa de pós-doutoramento para a realização da pesquisa $A$ Configuração das Políticas Sociais no Contexto do Federalismo Brasileiro do Século XXI, que está sendo desenvolvida na Universidade Estadual do Rio de Janeiro (UERJ), sob supervisão da Profa. Dra. Elaine Behring; assim como à Universidade de Brasília pela concessão da licença para o estágio pós-doutoral na UERJ, no período de 18/08/2013 a 17/08/2014.

* Economista. Mestre e doutor em política social pela Universidade de Brasília (UnB), onde é professor do Departamento de Serviço Social e do Programa de Pós-Graduação em Política Social. Pesquisador do Grupo de Estudos e Pesquisas em Seguridade Social e Trabalho (GESST/UnB). E-mail: evilasioss@unb.br
} 
Federal District and municipalities in budget functions: social assistance, health and education, from 2002 to 2012, highlighting the co-financing these social policies. As well as to identify some obstacles created by the fiscal adjustment underway in the country to expand the co-financing of social policies.

Keywords: Co-financing; Federalism; Social Policies

\section{Introdução}

O fundo público envolve toda a capacidade de mobilização de recursos que o Estado tem para intervir na economia, seja por meio das empresas públicas, seja pelo uso das suas políticas monetária e fiscal, seja pelo orçamento público (SALVADOR, 2012a; 2012b). Uma das principais formas da realização do fundo público é por meio da extração de recursos da sociedade na forma de impostos, contribuições e taxas, da mais-valia socialmente produzida, portanto, conforme Behring (2010), é parte do trabalho excedente que se transformou em lucro, juro ou renda da terra, sendo apropriado pelo Estado para o desempenho de múltiplas funções.

No estudo sobre o fundo público e orçamento público é fundamental que a análise não se limite apenas à investigação da alocação dos recursos, mas que compreenda como são financiadas as políticas públicas, sobretudo as sociais, no âmbito do Estado (SALVADOR; TEIXEIRA, 2014). A partir desse prisma, este texto toma como ponto de partida as seguintes questões: qual é a origem do recurso público? E quais características marcam o desenho federativo de cofinanciamento das políticas sociais no Brasil?

O arranjo federativo pós-Constituição de 1988 vem indicando a maior responsabilidade das unidades federativas e dos munícipios na execução das políticas sociais, ao mesmo tempo que se conferiu maior autonomia na arrecadação tributária.

Em que pese, a Constituição Federal (CF) de 1988 tem reforçado o processo de descentralização e de compartilhamento de atribuições entre a União, os estados e os municípios no campo das políticas sociais, o processo de ajuste fiscal e de implementação de políticas neoliberais nos anos de contrarreforma do Estado brasileiro (BEHRING, 2003) inviabilizaram os investimentos sociais para alimentar as despesas com o pagamento de juros e amortização de dívida pública, privilegiando a elite rentista financeira.

A partir dos anos 2000, as novas regulamentações das políticas sociais nas áreas de educação, saúde e assistência social vêm exigindo um maior esforço de recursos orçamentários dos estados, do Distrito Federal e dos municípios, sem a criação ou aporte de 
receitas fiscais adicionais. Isso tudo em um contexto de ajuste fiscal que submetem os entes subnacionais ao constrangimento de expansão dos investimentos sociais devido à Lei de Responsabilidade Fiscal (LRF) e ao comprometimento de parcela considerável das receitas dos estados e das grandes prefeituras com a dívida decorrente do refinanciamento feito pela União, em meados da década de 1990.

Nas políticas sociais, importantes mudanças legislativas marcam a primeira década do século XXI no Brasil, com implicações diretas no arranjo federativo e por consequência no cofinanciamento das políticas sociais, destacadamente: a Emenda Constitucional no 29/2000, que assegura recursos mínimos para o financiamento das ações e serviços públicos de saúde, regulamentada em 2011; a Norma Operacional Básica do Sistema Único da Assistência Social NOB/SUAS (Resolução 130 do Conselho Nacional de Assistência Social, de 15 de julho de 2005); e a criação do Fundo de Manutenção e Desenvolvimento da Educação Básica e de Valorização dos Profissionais da Educação (FUNDEB), em 2007.

Essa nova configuração das políticas sociais no federalismo brasileiro tem sido pouco estudada na área de conhecimento do Serviço Social. Além disso, as diversas políticas sociais não apresentam uma evolução homogênea na repartição das responsabilidades entre a União e os entes da federação no tocante à gestão e ao financiamento dos gastos com saúde, educação e assistência social.

Este texto apresenta alguns resultados parciais que integram uma pesquisa de pósdoutorado sobre a Configuração das Políticas Sociais no Contexto do Federalismo Brasileiro do Século XXI, desenvolvida no âmbito da Universidade Estadual do Rio de Janeiro (UERJ). O objetivo principal do texto é apresentar os primeiros resultados do levantamento feito sobre o montante de recursos aplicados pela União, estados, DF e municípios nas funções orçamentárias: assistência social, saúde e educação, no período de 2002 a 2012, evidenciando o confinaciamento dessas políticas sociais; assim como o de identificar alguns obstáculos criados pelo ajuste fiscal em curso no país para a expansão do cofinanciamento das políticas sociais.

\section{A Constituição Federal de 1988 e o arranjo federativo}

A partir da proclamação da República, o Brasil convive com o regime federativo de organização política, confirmado pela primeira Constituição republicana de 1891 . Francisco de Oliveira (1995) destaca que o federalismo brasileiro é resultado do empenho do poder 
central para assegurar a unidade territorial e preservar os interesses políticos e econômicos das oligarquias regionais constituídas durante o império.

Naquela Constituição, os recursos públicos foram canalizados para alguns poucos estados, o que indica que a federação no Brasil no seu nascedouro é marcada pela concentração de recursos e por escassas relações entre os entes constitutivos da federação, sendo uma federação isolada. Esse isolamento só foi interrompido, em 1930, durante o governo do presidente Vargas (SOUZA, 2005). Uma das consequências dessa estratégia foi o fortalecimento das regiões mais desenvolvidas economicamente, acentuando as desigualdades sociais e regionais, que até hoje caracterizam o país (CRUZ, 2012).

Ao longo da história brasileira existiu uma diversidade de arranjos federativos, sendo que as regras relativas ao federalismo esteve presente em todas as constituições, após a proclamação da República, com especificação das competências dos três níveis de governo, embora a Constituição de 1988 seja a mais detalhada (SOUZA, 2005). Aliás, um dos temas recorrentes nos estudos sobre a formação e as transformações da sociedade brasileira esta a relação entre centralismo e federalismo (IANNI, 2000).

O Brasil é um país regido por um modelo federativo que permite um arranjo políticoinstitucional entre os diversos níveis de governo (federal, estadual e municipal) que estabelece a cooperação e articulação entre o governo central (União) e os governos subnacionais, mas sem a superação das desigualdades sociais e econômicas entre as regiões brasileiras. De forma que hoje a União é composta por 26 estados, o Distrito Federal e 5.564 municípios, totalizando 5.592 entes e, conforme a Secretaria do Tesouro Nacional (2013), cada ente tem a obrigação de apresentar as próprias demonstrações contábeis conforme imposição legal.

Almeida (1996) faz uma análise do federalismo e das políticas sociais, retratando a passagem de uma forma extrema de federalismo centralizado, o Estado quase unitário (constituído nos regimes autoritários, que originou o sistema de proteção social brasileiro, na era Vargas - 1930/45 - e na época da ditadura militar - 1964-84), período em que as políticas sociais eram consideradas ineficazes e fragmentadas, para o federalismo cooperativo. Esta modalidade foi impulsionada na década de 1980 e diz respeito ao redesenho das funções do governo federal e aos processos diversos de realocação de recursos, consolidação e devolução de funções anteriormente concentradas no poder central e a descentralização das políticas sociais. Para a autora, há três tipos de arranjos federativos: federalismo dual, centralizado e o cooperativo. Em qualquer um destes arranjos, a maneira como são 
originados e distribuídos os recursos fiscais entre as esferas de governo é o eixo norteador, isto é, o federalismo fiscal (ALMEIDA, 1996).

A CF de 1988 no aspecto federativo fez uma opção por configuração de políticas sociais com competências concorrentes. Assim, segundo Arretche $(2004 ; 2012)$, se por um lado qualquer ente federativo ficou constitucionalmente autorizado a implantar programas sociais nas áreas de saúde, educação, assistência social, habitação e saneamento, por outro, nenhum ente federativo estava constitucionalmente obrigado a implementar programas nestas áreas. Com isso, vários autores (ALMEIDA, 1996; PALOS, 2011) afirmam que ao mesmo tempo que a Constituição descentralizou a arrecadação tributária não fez o mesmo no tocante às responsabilidades de execução das políticas sociais, ou seja, "não existiu uma correspondência necessária entre distribuição de encargos e receitas, fazendo com que alguns estados e municípios não consigam arcar com as novas atribuições" (AFFONSO, 2000, p. 137).

Para Prado (2006), a Constituição Federal (CF) de 1988 estabeleceu diretrizes fortemente descentralizadoras no que diz respeito à receita disponível e autonomia tributária dos governos subnacionais. Contudo, para Arretche (2004), a Constituição 1988 não conseguiu alterar a estrutura institucional na gestão das políticas sociais herdada da ditadura militar. Para esta autora, "a distribuição federativa ${ }^{1}$ dos encargos na área social derivava menos de obrigações constitucionais e mais da forma como historicamente estes serviços estiveram organizados em cada política particular" (ARRETCHE, 2004, p. 22).

No entanto, vale ressalvar que na CF de 1988 foram incorporadas importantes diretrizes (formulação, deliberação, monitoramento, avaliação e financiamento das políticas públicas) para a democratização e publicização do Estado brasileiro, notadamente, na gestão das políticas sociais; sendo que no processo da regulamentação dessas diretrizes constitucionais foram estruturados espaços públicos institucionais como os conselhos de políticas públicas e as conferências (MORONI, 2009).

Souza (2005) destaca que a Constituição estabelece competências concorrentes dos três níveis de governo para provisão compartilhada da maioria dos serviços públicos, em particular os sociais. Entretanto, há um hiato entre a prática e o comando constitucional, pois, para Souza (2005), o federalismo cooperativo esta longe de ser alcançado devido as desigualdades financeiras, técnicas e de gestão existentes entre os governos subnacionais.

\footnotetext{
${ }^{1}$ Na opinião de Arretche (2004), a gestão permaneceu centralizada para as políticas de saúde e desenvolvimento urbano e descentralizada para a política de educação fundamental.
} 
Além da ausência de "mecanismos constitucionais ou institucionais que estimulem a cooperação, tornando o sistema altamente competitivo" (SOUZA, 2005, p.112). Também não foi editada a lei complementar prevista no artigo 23 da CF, que teria por objetivo fixar as normas para a cooperação entre a União e os estados, Distrito Federal e os municípios, tendo em vista o equilíbrio do desenvolvimento e do bem-estar no país.

No tocante às competências tributárias, a CF de 1988 estabeleceu (Título VI, Cap. I) que o Imposto sobre a Renda e Proventos de Qualquer Natureza - pessoa física e jurídica - (IR), o Imposto sobre Produtos Industrializados (IPI), o Imposto sobre a Propriedade Territorial Rural $(\text { ITR })^{2}$ e tributos sobre grandes fortunas, além das contribuições sociais para a Seguridade Social, são de competência federal. O Imposto sobre Propriedade de Veículos Automotores (IPVA), o Imposto sobre Transmissão Causa Mortis e Doação (ITCD) e o Imposto sobre Circulação de Mercadorias e Serviços (ICMS) são de competência estadual. ${ }^{3}$ Por fim, o Imposto Predial e Territorial Urbano (IPTU) e o Imposto de Transmissão de Bens Imóveis Inter Vivos (ITBI) são de responsabilidade dos municípios. Sendo que o Distrito Federal tem a dupla competência de instituir impostos de caráter estadual e municipal.

Uma parcela da arrecadação dos impostos federais é transferida diretamente para os estados e munícipios por meio do Fundo de Participação dos Estados (FPE) e do Fundo de Participação dos Municípios (FPM), que foram criados na reforma tributária de 1965/68. Conforme Prado (2006), esses fundos foram valorizados com a Constituição de 1988, aumentando os percentuais de apropriação do IR e do IPI que eram de 5\%, em 1968, e passaram a $21,5 \%$ (FPE) e $22,5 \%$ (FPM).

A CF de 1988 confirmou, no campo das finanças públicas, os processos de reordenamento institucional e de unificação do orçamento, além de ampliar o fortalecimento da federação e do papel do Congresso Nacional, recuperando as prerrogativas do Poder Legislativo em matéria orçamentária ${ }^{4}$. Guardia (1997) destaca três grupos de modificações introduzidas pela Constituição no processo orçamentário: a) a tentativa de recuperar o papel de planejador do Estado com a integração entre plano e orçamento; b) a conclusão do

\footnotetext{
${ }^{2}$ A Lei no 11.250 de 2005 prevê a possibilidade de convênios entre a União e o DF e municípios para fiscalizar e arrecadar o ITR.

${ }^{3}$ A competência estadual dos três tributos mencionados foi instituída pela Emenda Constitucional no 3, de 1993.

${ }^{4}$ Ver, nesse sentido, o quadro comparativo do orçamento público nas Constituições Federais de 1967 e 1988 elaborado por Piscitelli, Timbó e Rosa (2006, p. 60 a 69), capítulo 4.
} 
processo de unificação orçamentária; e c) a recuperação da competência do Congresso Nacional para dispor de matéria orçamentária.

No tocante à questão do planejamento, isso ocorre pela criação de duas peças orçamentárias: o Plano Plurianual (PPA) e a Lei de Diretrizes Orçamentárias (LDO). Com isso, a partir da CF, o ciclo orçamentário é composto pelo PPA, pela LDO e pela Lei Orçamentária Anual (LOA). O objetivo principal dessas leis é integrar as atividades de planejamento e orçamento, visando garantir a execução das políticas governamentais nos municípios, estados, Distrito Federal e em âmbito nacional.

Contudo, orçamento não se limita a uma peça técnica e formal ou a um instrumento de planejamento; ele é, desde suas origens, uma peça de cunho político (OLIVEIRA, 2009), portanto, ele serve para orientar as negociações sobre quotas de sacrifício acerca dos membros da sociedade no tocante ao financiamento do Estado e é utilizado como instrumento de controle e direcionamento dos gastos. Assim, a decisão sobre os objetivos de gastos do Estado e a fonte dos recursos para financiá-lo não é somente econômica, mas são principalmente escolhas políticas, refletindo a correlação de forças sociais e políticas atuantes e que têm hegemonia na sociedade (OLIVEIRA, 2009). Os gastos orçamentários definem a direção e a forma de ação do Estado nas suas prioridades de políticas públicas.

\section{Cofinanciamento das políticas sociais no orçamento público}

Para Oliveira (2009), o orçamento deve ser visto como o espelho da vida política de uma sociedade, à medida que registra e revela, em sua estrutura de gastos e receitas, sobre que classe ou fração de classe recai o maior ou o menor ônus da tributação e as que mais se beneficiam com os seus gastos. Por meio do orçamento público, o Poder Executivo procura cumprir determinado programa de governo ou viabilizar objetivos macroeconômicos. A escolha do programa a ser implementado pelo Estado e dos objetivos de política econômica e social reflete os interesses das classes, envolvendo negociações de seus representantes políticos, na qual o orçamento é a expressão das suas reivindicações.

As despesas financeiras referentes ao pagamento de juros e amortização da dívida são as que mais comprometem o fundo público no Brasil. O dilema do orçamento público brasileiro não se encontra na dicotomia despesas de investimento versus custeio. Ambas são fundamentais e necessárias para o desenvolvimento econômico e social do país. A questão central é se o Brasil vai continuar refém dos rentistas do capital financeiro ou vai priorizar a 
construção de um sistema de proteção social, com expansão de investimentos (SALVADOR, TEIXEIRA, 2014). As despesas com saúde e educação estão abaixo dos padrões internacionais dos países da Organização para a Cooperação e Desenvolvimento Econômico (OCDE). Assim como nos últimos anos não foram priorizadas no orçamento público as despesas e os investimentos necessários à universalização das políticas sociais.

Levantamento realizado por Salvador e Teixeira (2014) revela que o serviço da dívida compromete uma parcela importante dos orçamentos da seguridade social e fiscal, seja na forma de juros e encargos da dívida, seja no pagamento de amortização da dívida para o setor financeiro da economia. No período de 2008 a 2012, excetuando o ano de 2011, os gastos com pagamento de juros e amortização da dívida permaneceram acima de $1 / 4$ do valor total do orçamento chegando, em 2012, a apropriar-se de 32,12\% do montante total de recursos do orçamento público, isto é, foram destinados 481,18 bilhões para o serviço da dívida, excetuando o refinanciamento. Pochmann et al. (2004) estimam que $80 \%$ do pagamento dos juros da dívida pública sejam destinados a somente 20 mil famílias de rentistas, que vivem a custas do fundo público brasileiro.

Sendo que o financiamento do fundo público brasileiro é extremamente regressivo, onerando os mais pobres em detrimento de taxações sobre os mais ricos na sociedade. A carga tributária que expressa a relação entre o volume de recursos que o Estado extrai da sociedade, sob a forma de impostos, taxas e contribuições para financiar as atividades que se encontram sob sua responsabilidade; e o Produto Interno Bruto (PIB) elevou-se de 33,20\%, em 2000, para 35,31\%, em 2011. Os tributos incidentes sobre o consumo representavam $55,74 \%$ sobre o total da arrecadação tributária da União, do Distrito Federal (DF), dos Estados e dos Municípios, no entanto, os tributos incidentes sobre a renda representam apenas 10,76\% do PIB e a Carga Tributária sobre patrimônio 1,31\% do PIB, em 2011 (SALVADOR, 2014).

Contudo, conforme Salvador e Teixeira (2014), no período de 2008 a 2012, as despesas com amortização da dívida cresceram quase cinco vezes acima dos gastos com pessoal e encargos sociais. As despesas de pessoal e encargos sociais estão estacionadas em relação ao Produto Interno Bruto (PIB), que, em 2008, equivaliam a 4,38\%, e, em 2012, $4,29 \%$ do PIB.

De acordo com os autores citados, dos $\mathrm{R} \$ 751,63$ gastos em outras despesas correntes, em 2012, 43,71\% referem-se aos benefícios previdenciários do Regime Geral da Previdência 
Social e do Regime Próprio dos Servidores Públicos Federais, incluindo o pagamento de inativos, pensões e outros benefícios previdenciários a mais de 32 milhões de pessoas. As transferências aos estados, Distrito Federal e municípios representam 1/4 das outras despesas correntes, restando para as demais despesas correntes no âmbito dos orçamentos fiscal e da seguridade social da União, R\$228,79 bilhões. Essas despesas são destinadas a execução das políticas sociais do governo, além dos gastos com aquisição de material de consumo, pagamento de diárias, contribuições e subvenções.

Convém ressaltar que a CF de 1988 assegurou algumas despesas obrigatórias, destinadas aos direitos sociais (seguridade social, seguro-desemprego e educação) no orçamento público e que provocam a reação conservadora, dos que reclamam do "engessamento" do orçamento público. ${ }^{5}$ As despesas obrigatórias executadas pela União, por determinação constitucional ou de lei, não podem ser contingenciadas para realizar superávit primário.

Destacam-se nas despesas obrigatórias: i) benefícios previdenciários do Regime Geral de Previdência Social (RGPS); ii) benefícios concedidos pela Lei Orgânica da Assistência Social (LOAS) e pela Renda Mensal Vitalícia (RMV), em extinção - na qual determinam o pagamento de um salário mínimo de benefício mensal à pessoa portadora de deficiência e ao idoso que viva em família cuja renda mensal per capita seja inferior a $1 \frac{1}{4}$ do salário mínimo; iii) o abono salarial e o seguro desemprego; iv) gastos mínimos com saúde.

Os efeitos da vinculação orçamentária às políticas sociais específicas asseguram os gastos mínimos em políticas de saúde e educação também no âmbito dos municípios e dos estados. Arretche $(2010 ; 2012)$ destaca na gestão das políticas sociais a existência de dois tipos de políticas descentralizadas: a) reguladas, em que a legislação e a supervisão federal colocam limites na autonomia decisória dos governos subnacionais, assegurando assim gastos orçamentários obrigatórios em determinadas políticas sociais; e b) não reguladas, que são aquelas nas quais a execução das políticas sociais esta associada à autonomia das decisões dos governos locais.

O corolário da legislação pós-Constituição é que pelo menos $40 \%$ das receitas municipais devem ser alocadas nas áreas de saúde e educação - 25\% para a educação e 15\% para a saúde. Enquanto as políticas não reguladas, ou seja, sem a vinculação de gastos e receitas, como

\footnotetext{
${ }^{5}$ Por exemplo, o estudo de Mendes (2009). 
àquelas vinculadas ao desenvolvimento urbano (habitação e saneamento) padecem da vontade do governante na alocação orçamentária, não sendo políticas nem universais e nem regulares (ARRETCHE, 2010). Tal situação é rotina no orçamento federal, com as políticas sociais que dependem dos gastos discricionários apresentando uma baixa execução orçamentária, ${ }^{6}$ destacadamente: habitação, saneamento, urbanismo e direitos da cidadania, enquanto os gastos orçamentários com previdência, assistência social, saúde, educação e trabalho conseguem preservar a sua execução, pois têm a maior parte dos recursos de natureza obrigatória e vinculada (SALVADOR, 2010).

A situação do federalismo brasileiro vem se tornando mais complexa, sobretudo, a partir dos anos 2000, com a emergência de políticas sociais descentralizadas e focalizadas (LEITE; FONSECA, 2011). Por um lado, nos programas de transferência de renda como o Bolsa Família, o governo federal buscar relacionar-se diretamente com os municípios (AFONSO, 2007), por outro, vem aumentando a responsabilidade dos entes federados com gastos sociais nas chamadas políticas universais (saúde e educação).

Nas políticas sociais, as mudanças legislativas marcam a primeira década do século XXI no Brasil com implicações diretas no arranjo federativo. Entre as mudanças, destaca-se a Emenda Constitucional no 29/2000, que assegura recursos mínimos para o financiamento das ações e serviços públicos de saúde, regulamentada em 2011 e que levou a maior participação dos estados e municípios no custeio da saúde (MELAMED; PIOLA, 2011); a publicação do novo texto da Política Nacional de Assistência Social (PNAS), em 2004, e da Norma Operacional Básica do Sistema Único da Assistência Social NOB/SUAS, em 2005, com as alterações normativas para a reorganização da proteção socioassistencial, em um sistema descentralizado e cofinanciado por estados e municípios (MESQUITA; MARTINS; CRUZ, 2012); e a criação do Fundo de Manutenção e Desenvolvimento da Educação Básica e de Valorização dos Profissionais da Educação (FUNDEB), em 2007, com importantes repercussões no pacto federativo (MARTINS, 2011).

Para alguns autores, trata-se de um novo padrão de relacionamento entre o governo federal e os entes federativos com "a lógica da institucionalização de sistemas", em que normativas institucionais e legais descentralizam ações, programas e recursos da esfera federal, com a obrigação de adequação dos governos subnacionais e a configuração das

\footnotetext{
6 Refere-se à comparação das dotações orçamentárias autorizadas com os recursos que foram liquidados no Orçamento Geral da União. Ver nesse sentido tabela 6 (p. 187) de Salvador (2010).
} 
políticas sociais do governo central, constituindo-se os sistemas nacionais (LEITE; FONSECA, 2011, p. 101).

Em que pese a CF de 1988 indicar como umas das diretrizes da seguridade social a descentralização, e a Lei Orgânica da Assistência Social (LOAS) de 1993 reforçar esse princípio, foi somente a partir da Política Nacional de Assistência Social (PNAS) e da implementação do SUAS, já no século XXI, que os princípios da descentralização político- administrativa e da gestão compartilhada entre os entes da federação passou a ser incorporado de forma mais contundente na política de assistência social.

Na esfera da política de assistência social, a descentralização foi concebida de forma que normas e regras gerais ficassem sob o comando da esfera federal (União), e a coordenação e execução dos programas sobre o comando das esferas subnacionais (RIBEIRO, 2013). Os princípios que orientam a atual política de assistência social no Brasil estão estabelecidos na PNAS/2004, indicando a direção da universalidade, da descentralização políticoadministrativa e do estabelecimento de um comando único nas esferas de gestão, de articulação e intersetorização das ações socioassistenciais (FREITAS, 2011). O SUAS é determinante para a operacionalização da LOAS, possibilitando a construção de um sistema descentralizado e participativo, assim como a sua regulação em todo o território nacional (MDS, 2004; 2005).

Uma das questões essenciais no federalismo fiscal, fundamental para o custeio das políticas sociais, é o cofinanciamento das responsabilidades entre os níveis de governo. Sendo viabilizado no Brasil por meio de transferências constitucionais e da descentralização de recursos orçamentários fundo a fundo (DAIN, 2001). Conforme Castro (2012), as novas regras de financiamento da política de assistência social, após o SUAS, definem critérios de partilha dos recursos no Fundo Nacional de Assistência Social (FNAS), objetivando equalizar, priorizar e projetar a universalização da cobertura de cofinanciamento em todo o território nacional.

A atual NOB/SUAS (2012) define claramente as competências dos entes da federação no tocante à gestão e suas competências no financiamento da política de assistência social.

A tabela 1 mostra os recursos destinados ao financiamento da política de assistência social, no período de 2002 a 2012, permitindo analisar a situação orçamentária desta política após o SUAS. Em que pese, as orientações no caminho da descentralização da assistência social e da definição das competências dos entes subnacionais, a União permanece como a principal financiadora desta política. 
No período de 2002 a 2012, o orçamento total da política da assistência social (União, DF, estados e municípios) cresceu 145,43\%, em valores deflacionados pelo IGP-DI. Contudo, esse acréscimo não foi homogêneo. Enquanto a União $(288,02 \%)$ e os municípios $(85,45 \%)$ aumentaram o destino de recursos orçamentários para a assistência social, os estados reduziram ao longo do século XXI o investimento nesta política, conforme tabela 1.

Tabela 1 -

Gastos com Assistência Social por Entes da Federação Em R\$ bilhões, deflacionados pelo IGP-DI (médio), a preços de 2012

\begin{tabular}{crrrrrrr}
\hline \hline & & & & \multicolumn{5}{c}{ Participação em \% } \\
Ano & União & Estados & Municípios & \multicolumn{1}{c}{ Total } & União & Estados & Municípios \\
\hline 2002 & 15,47 & 9,52 & 5,76 & 30,74 & $50,31 \%$ & $30,97 \%$ & $18,72 \%$ \\
2003 & 17,61 & 4,52 & 7,39 & 29,51 & $59,66 \%$ & $15,31 \%$ & $25,03 \%$ \\
2004 & 23,62 & 3,02 & 5,66 & 32,30 & $73,13 \%$ & $9,34 \%$ & $17,52 \%$ \\
2005 & 24,61 & 3,59 & 5,40 & 33,60 & $73,25 \%$ & $10,69 \%$ & $16,06 \%$ \\
2006 & 31,67 & 3,81 & 6,38 & 41,86 & $75,65 \%$ & $9,11 \%$ & $15,24 \%$ \\
2007 & 35,70 & 3,79 & 8,11 & 47,60 & $74,99 \%$ & $7,97 \%$ & $17,04 \%$ \\
2008 & 39,65 & 3,97 & 8,89 & 52,51 & $75,50 \%$ & $7,57 \%$ & $16,93 \%$ \\
2009 & 41,20 & 4,43 & 8,92 & 54,55 & $75,53 \%$ & $8,13 \%$ & $16,34 \%$ \\
2010 & 47,48 & 4,82 & 10,76 & 63,06 & $75,30 \%$ & $7,64 \%$ & $17,06 \%$ \\
2011 & 52,40 & 5,08 & 10,45 & 67,93 & $77,14 \%$ & $7,47 \%$ & $15,38 \%$ \\
2012 & 60,01 & 4,77 & 10,67 & 75,45 & $79,54 \%$ & $6,32 \%$ & $14,15 \%$ \\
\hline Var. \% 2002 a 2012 & $288,02 \%$ & $-49,93 \%$ & $85,45 \%$ & $145,43 \%$ & & & \\
\hline \hline
\end{tabular}

Fonte: Secretaria do Tesouro Nacional (STN)

Elaboração própria

Nota:

1) Nos estados inclui o Distrito Federal.

Antes do SUAS, em 2003, a União respondia por 59,66\% do financiamento da assistência social, aumentando sua participação no período para 79,54\%, em 2012. Paralelamente os municípios e os estados reduziram a participação no período (tabela 1). Isso se deve a "histórica tendência de concentração de recursos nos benefícios monetários (BPC e RMV), o que fragiliza a possibilidade de consolidação do SUAS nos municípios" (BOSCHETTI; TEIXEIRA; SALVADOR; 2013, p. 31); sendo que os recursos destinados à transferência de renda ganharam mais peso, a partir da implantação do Programa Bolsa Família (PBF), em 2004. Os recursos destinados ao BPC, RMV e PBF respondem por $90 \%$ do orçamento federal da assistência social (SALVADOR, 2011).

No entanto, conforme destacam Mesquista, Martins e Cruz (2012), os municípios são os principais financiadores dos serviços socioassistenciais. Em 2009, conforme as autoras, excluindo os benefícios pagos pela União, o gasto com assistência social alcançou $R \$ 12,03$ 
bilhões, sendo $R \$ 5,87$ bilhões dos orçamentos dos municípios, $R \$ 3,31$ bilhões da União (sem benefícios) e $\mathrm{R} \$ 2,75$ bilhões do Estado.

Entre as dificuldades apontadas por Mesquista, Martins e Cruz (2012) esta a ausência de definição legal de percentual de participação de cada ente federado no cofinanciamento da política de assistência social, além da reduzida participação da esfera estadual no cofinanciamento. Para Boschetti, Teixeira e Salvador (2013), o cofinanciamento segue sendo um dos elos mais frágeis do SUAS. Com base no Censo SUAS de 2011, os autores apontam que $47 \%$ dos municípios não recebem recursos dos Estados, isto é, quase a metade dos municípios brasileiros depende exclusivamente dos repasses federais e de seu próprio orçamento.

A política de saúde desde a Constituição de 1988 encontra dificuldades de viabilizar o seu financiamento, que garanta a universalização desta política. Na realidade, o Brasil vive um paradoxo, possivelmente o único país com sistema universal de saúde em que o gasto privado é maior que o público (PIOLA; VIANNA, 2008). Além da universalidade, a Constituição definiu os princípios e as diretrizes do Sistema Único de Saúde (SUS) e da integralidade da atenção e descentralização das ações.

A política de saúde integra a Seguridade Social, juntamente com a Previdência e a Assistência Social, sendo que o Art. 196 da CF de 1988 estabelece que a saúde é um direito de todos e dever do Estado, constituindo-se uma política universal e não contributiva. As competências dos entes federativos estão dispostas nos artigos 16, 17, 18 e 19 da Lei 8.080, com as ações e obrigações dos municípios, estados, DF e União.

$\mathrm{Na}$ tentativa de assegurar recursos suficientes para o financiamento da política de saúde foi estabelecido, no artigo 55, do Ato das Disposições Constitucionais Transitórias a destinação de, no mínimo, 30\% do Orçamento da Seguridade Social até que fosse aprovada a primeira Lei de Diretrizes Orçamentárias (LDO). Determinação não cumprida nos últimos 25 anos.

Conforme Piola et al. (2013), no tocante ao financiamento, o maior desafio era redirecionar parcela significativa de recursos do fundo público para ampliar a cobertura de ações e serviços de saúde para toda a população. Sendo assim, para viabilizar a descentralização era necessário, conforme os autores, "ampliar a participação de estados e municípios no financiamento do SUS e transferir para a gestão de estados e municípios 
recursos até então majoritariamente administrados pelo governo federal" (PIOLA et al., 2013, p. 8).

Após inúmeros caminhos e descaminhos, o financiamento da saúde ${ }^{7}$ foi definido pela Emenda Constitucional (EC) № 29, que entrou em vigor em 2000 e regulamentado pela Lei Complementar no 141, de 13 de janeiro de 2012. A EC no 29 estabelece a vinculação de recursos orçamentários da União, estados e municípios para as despesas de saúde, tendo como ponto de partida o valor executado em 1999, acrescido de $5 \%$.

Para os anos 2001 a 2004, deveria ser utilizado o valor apurado no ano anterior, corrigido pela variação nominal do PIB. Os estados devem destinar $12 \%$ dos impostos e outras receitas para o financiamento das ações e serviços de saúde. Os municípios e também o Distrito Federal devem destinar $15 \%$ do produto da arrecadação dos impostos e outros recursos especificados nos Artigos 156, 158 e 159 da Constituição. Mas, a falta de regulamentação da $\mathrm{EC} n$ ㅇ 29 gerou uma série de controvérsias, entre elas as discussõesacerca da base sobre a qual incidiria a correção correspondente à variação nominal do PIB, para a determinação do montante dos recursos federais. Além do não cumprimento dos mínimos constitucionais de gastos com saúde por parte dos estados e dos municípios (PIOLA et al., 2013).

A regulamentação da Emenda poderia abrir assim uma "janela de oportunidades" a fim de ampliar recursos para o SUS e estabelecer medidas claras para evitar o descumprimento da Constituição. Piola et al. (2013) também destacam que apesar dos avanços de recursos para a saúde nos últimos anos, observa-se que a União, mesmo tendo aumentando sua participação na Carga Tributária, vem reduzindo sua presença no custeio desta política. Além disso, o esforço dos municípios já estava no limite e muitos estados enfrentavam problemas reais para cumprir aplicação dos recursos mínimos determinado na CF de 1988.

Piola et al. (2013), ao analisarem várias legislações que tratam do cofinanciamento e da descentralização da política de saúde, no período após a Constituição de 1988, destacam que:

a) o repasse fundo a fundo ganhou espaço como forma de transferência dos recursos federais para os entes subnacionais a aplicação direta na área hospitalar e ambulatorial e convênios em outras áreas; e

\footnotetext{
${ }^{7}$ Mais detalhes do financiamento da política de saúde no período de 1988 a 2012 pode ser visto em Piola et al. (2013).
} 
b) o automatismo dessa forma de repasse dos recursos federais ficou distante da concepção preconizadas por alguns defensores da descentralização que defendiam a utilização de critérios predefinidos e partilha já na origem dos recursos, nos moldes do FPE e do FPM.

O corolário da regulamentação do financiamento é uma alteração na responsabilidade dos gastos públicos com saúde no Brasil; em 2000, os estados e municípios respondiam por $40,14 \%$ do total dos gastos públicos com saúde (SALVADOR, 2010). Esses entes subnacionais aumentaram a participação no custeio da saúde de 53,72\%, em 2002, para 64,42\%, em 2012 (tabela 2). Ao mesmo tempo que ocorreu um decréscimo da participação federal nos gastos públicos com saúde de 59,86\%, em 2000 (SALVADOR, 2010), depois para 46,8\%, em 2002, reduzindo-se para 35,58\%, em 2012, conforme a tabela 2. Os dados revelam que a EC 29 foi parcialmente bem-sucedida, no sentido de ampliar a participação dos estados e dos municípios nos gastos com saúde pública.

\section{Tabela 2}

Gastos com Saúde por Entes da Federação Em R\$ bilhões, deflacionados pelo IGP-DI (médio), a preços de 2012

\begin{tabular}{crrrrrrr}
\hline \hline & & & & \multicolumn{3}{c}{ Participação em \% } \\
Ano & União & Estados & Municípios & Total & União & Estados & Municípios \\
\hline 2002 & 60,40 & 29,54 & 40,55 & 130,49 & $46,28 \%$ & $22,64 \%$ & $31,08 \%$ \\
2003 & 56,85 & 41,53 & 50,17 & 148,55 & $38,27 \%$ & $27,96 \%$ & $33,77 \%$ \\
2004 & 56,18 & 44,44 & 42,88 & 143,49 & $39,15 \%$ & $30,97 \%$ & $29,88 \%$ \\
2005 & 56,81 & 46,61 & 41,02 & 144,45 & $39,33 \%$ & $32,27 \%$ & $28,40 \%$ \\
2006 & 58,40 & 50,28 & 48,11 & 156,79 & $37,25 \%$ & $32,07 \%$ & $30,69 \%$ \\
2007 & 64,91 & 54,90 & 60,09 & 179,90 & $36,08 \%$ & $30,52 \%$ & $33,40 \%$ \\
2008 & 67,66 & 61,83 & 66,81 & 196,30 & $34,47 \%$ & $31,50 \%$ & $34,04 \%$ \\
2009 & 71,87 & 62,56 & 70,76 & 205,19 & $35,03 \%$ & $30,49 \%$ & $34,49 \%$ \\
2010 & 73,61 & 67,64 & 81,35 & 222,60 & $33,07 \%$ & $30,39 \%$ & $36,55 \%$ \\
2011 & 81,50 & 66,63 & 80,13 & 228,27 & $35,71 \%$ & $29,19 \%$ & $35,10 \%$ \\
2012 & 83,29 & 68,42 & 82,38 & 234,09 & $35,58 \%$ & $29,23 \%$ & $35,19 \%$ \\
\hline Var. \% 2002 a 2012 & $37,90 \%$ & $131,62 \%$ & $103,15 \%$ & $79,39 \%$ & & & \\
\hline \hline
\end{tabular}

Fonte: Secretaria do Tesouro Nacional (STN)

Elaboração própria

Nota:

1) Nos estados inclui o Distrito Federal.

Os dados da consolidação das Contas Públicas da Secretaria do Tesouro Nacional revelam que no período de 2004 a 2012, excetuando o refinanciamento das dívidas (federal, dos estados, do DF e dos municípios), o orçamento fiscal e da seguridade social cresceu na esfera da União 74,05\% acima da inflação, mas os gastos com saúde no orçamento apresentam um crescimento bem mais modesto, $48,26 \%$. Enquanto nos municípios, os gastos 
com saúde aumentaram 92,12\% superando o crescimento de $81,45 \%$, verificado nos orçamentos fiscal e da seguridade social, no mesmo período.

No tocante à política de educação, convém lembrar que ela é a única política social executada no orçamento fiscal da União, com recursos vinculados e de gastos obrigatórios, o que garante uma relativa estabilidade nas fontes orçamentárias ao longo dos anos (SALVADOR, 2012b). Como lembrado por Abrahão (2004), o financiamento público da educação no Brasil foi consolidado na CF de 1988 e na Lei de Diretrizes de Bases da Educação Nacional (LDB), que atribuíram à União, aos estados, ao DF e aos municípios a responsabilidade pela administração do sistema educacional brasileiro, consagrando a existência de três sistemas de ensino público, tendo como fundamento o regime de colaboração entre essas instâncias federadas.

No Brasil, uma das formas de enfrentar a perversa tradição do orçamento fiscal foi a criação dos fundos sociais para assegurar a ampliação dos direitos sociais, por meio do orçamento público. Para a política educacional, a Constituição assegura que a União deve destinar $18 \%$ da arrecadação dos impostos vinculando $25 \%$ das receitas dos estados, do Distrito Federal e dos municípios à educação.

A Emenda Constitucional no 14 de 1996 assinala a divisão de responsabilidades entre os entes da federação no que concerne o sistema de ensino, sendo a União responsável por organizar o sistema federal de ensino, financiar as instituições de ensino público federal e exercer a função redistributiva e complementar, por meio de assistência técnica e financeira, os estados e municípios. Os estados e o Distrito Federal são responsáveis por atuar prioritariamente no ensino médio e assegurar o ensino fundamental; enquanto, os municípios atuam prioritariamente no ensino fundamental e educação infantil.

Nesse contexto, entre a definição de responsabilidades e as fontes de recursos para a educação pública, insere-se a discussão sobre fundos públicos para financiar e repartir os recursos financeiros entre os entes da federação, conforme Gemarque (2011).

Destaque-se que o Fundo de Manutenção e Desenvolvimento do Ensino Fundamental e de Valorização do Magistério (Fundef) foi instituído pela Emenda Constitucional no 14/96, regulamentado pela Lei no 9.424/96 e pelo Decreto no 2.264/97, tendo a sua implantação nacional em 10 de janeiro de 1998, quando passou a vigorar a nova sistemática de redistribuição dos recursos destinados ao ensino fundamental. A principal inovação foi na mudança da estrutura de financiamento do ensino fundamental no país (1a a $8^{a}$ séries 
do antigo 1ㅇ grau), ao subvincular a esse nível de ensino uma parcela dos recursos constitucionalmente destinados à educação. A partir da criação do Fundef, $60 \%$ desses recursos (o que representa $15 \%$ da arrecadação global de estados e municípios) ficam reservados ao ensino fundamental (GUILHERME; SALVADOR, 2013).

O segundo passo importante, após a Constituição de 1988, para assegurar e ampliar os recursos para a educação foi a criação, pela Emenda Constitucional no 53/2006, do Fundo de Manutenção e Desenvolvimento da Educação Básica e de Valorização dos Profissionais da Educação (Fundeb), em substituição ao Fundef, que vigorou de 1998 a 2006.

O Fundeb é um fundo especial, de natureza contábil e de âmbito estadual, formado, na quase totalidade, por recursos provenientes dos impostos e transferências dos estados, Distrito Federal e municípios, vinculados à educação, por força do disposto no art. 212 da Constituição Federal. Além dessas receitas, ainda compõe o Fundeb, a título de complementação, uma parcela de recursos federais, sempre que, no âmbito de cada estado, seu valor por aluno não alcançar o mínimo definido nacionalmente. A vigência estabelecida é para o período 2007-2020, começando em 2007 e sendo plenamente concluída em 2009, quando o total de alunos matriculados na rede pública foi considerado na distribuição dos recursos, e o percentual de contribuição dos estados, Distrito Federal e municípios, para a formação do Fundo, atingiu o patamar de 20\% (GUILHERME; SALVADOR, 2013).

De acordo com o Fundo Nacional de Desenvolvimento da Educação (FNDE) (2012), ${ }^{8}$ o aporte de recursos do governo federal ao Fundeb, de $R \$ 2$ bilhões em 2007, aumentou para $\mathrm{R} \$ 3,2$ bilhões, em 2008, R\$5,1 bilhões, em 2009 e, a partir de 2010, passou a ser no valor correspondente a $10 \%$ da contribuição total dos estados e municípios de todo o país.

De fato, os dados da tabela 3 revelam uma maior responsabilização da União no financiamento da educação. Os gastos federais com educação cresceram 120,62\% acima da inflação. Com isso, a União aumentou a sua participação no financiamento orçamentário da educação de 23,51\% (2002) para 28,04\% (2012). De acordo com os dados da tabela 3,

\footnotetext{
${ }^{8}$ O FNDE é uma autarquia federal, ligada diretamente ao Ministério da Educação (MEC) e responsável direto pela aplicação de recursos financeiros em programas relacionados à educação. É responsável por prestar assistência técnico-financeira na implementação de recursos para programas vinculados à educação propiciando a melhoria na qualidade do ensino público ofertado à população brasileira. Em suma, o FNDE dispõe de recursos do Tesouro Nacional e os repassa aos entes federativos (União, estados e municípios), por meio de contas correntes específicas e destinadas exclusivamente para a execução dos programas educacionais que, previamente, são autorizados pelo fundo. Mais dados em: <www.fnde.gov.br>.
} 
depois da União, os municípios apresentaram o maior incremento de gastos orçamentários, indicando um maior avanço no financiamento dos ensinos fundamental e infantil.

\section{Tabela 3}

Gastos com Educação por Entes da Federação Em R\$ bilhões, deflacionados pelo IGP-DI (médio), a preços de 2012

\begin{tabular}{cccrcccc}
\hline \hline & & & & \multicolumn{5}{c}{ Participação em \% } \\
Ano & União & Estados & Municípios & Total & União & Estados & Municípios \\
\hline 2002 & 31,40 & 55,09 & 47,05 & 133,54 & $23,51 \%$ & $41,26 \%$ & $35,23 \%$ \\
2003 & 29,76 & 81,35 & 57,93 & 169,04 & $17,60 \%$ & $48,13 \%$ & $34,27 \%$ \\
2004 & 24,76 & 66,37 & 46,35 & 137,48 & $18,01 \%$ & $48,28 \%$ & $33,71 \%$ \\
2005 & 25,21 & 66,89 & 45,43 & 137,53 & $18,33 \%$ & $48,64 \%$ & $33,03 \%$ \\
2006 & 25,48 & 71,69 & 51,88 & 149,04 & $17,09 \%$ & $48,10 \%$ & $34,81 \%$ \\
2007 & 31,06 & 78,80 & 67,89 & 177,75 & $17,47 \%$ & $44,33 \%$ & $38,20 \%$ \\
2008 & 34,47 & 92,18 & 74,20 & 200,85 & $17,16 \%$ & $45,90 \%$ & $36,94 \%$ \\
2009 & 45,34 & 87,23 & 76,55 & 209,12 & $21,68 \%$ & $41,71 \%$ & $36,61 \%$ \\
2010 & 53,50 & 91,41 & 89,16 & 234,07 & $22,86 \%$ & $39,05 \%$ & $38,09 \%$ \\
2011 & 60,85 & 99,89 & 88,87 & 249,61 & $24,38 \%$ & $40,02 \%$ & $35,60 \%$ \\
2012 & 69,27 & 89,34 & 88,45 & 247,07 & $28,04 \%$ & $36,16 \%$ & $35,80 \%$ \\
\hline Var. \% 2000 a 2012 & $120,62 \%$ & $62,16 \%$ & $88,01 \%$ & $85,01 \%$ & & & \\
\hline \hline
\end{tabular}

Fonte: Secretaria do Tesouro Nacional (STN)

Elaboração própria

Nota:

1) Nos estados inclui o Distrito Federal.

O acréscimo de recursos na esfera da União é também consequência do fim da DRU sobre os gastos orçamentários com educação, aprovado em julho de 2008 . Assim como as políticas da seguridade social, o financiamento da educação foi prejudicado no período pelos desvios de recursos realizados por meio da DRU. Na educação, estima-se que os mecanismos de desvinculação de recursos (FSE , FEF e DRU) retiraram, em 12 anos (1994 a 2006) e em valores corrigidos pela inflação, $\mathrm{R} \$ 72$ bilhões (IWASSO; CAFARDO, 2007). Apenas no período de vigência da DRU (2000 a 2007), R\$45,8 bilhões deixaram de ser aplicados no setor. Em 2007, o Ministério da Educação (MEC) deixou de contar com R\$7,1 bilhões. O mecanismo é muito simples: a Constituição determina que $18 \%$ dos recursos arrecadados em impostos federais sejam aplicados em Educação, mas esse valor é calculado após a retirada dos recursos da DRU. Por consequência, em vez dos $18 \%$ previstos na Carta Magna são aplicados somente $13 \%$ na educação.

Cabe destacar que esta em curso um conjunto de contrarreformas, conforme Cislaghi (2012), no ensino superior no Brasil, em particular, com a transferência de recursos do fundo público para o setor privado por meio do Programa Universidade para Todos (Prouni) e da 
principal política de expansão do ensino superior púbico que é chamado de Reestruturação e Expansão das Universidades Federais (Reuni).

O Fundeb, com duração prevista de 14 anos, vai cobrir as três etapas do processo de formação educacional do cidadão (ou da educação básica): a educação infantil, a educação fundamental e a educação média. A distribuição das parcelas de competência é igual à do Fundef (União: 18\%; estados e DF: 25\%; municípios: 25\%). No entanto, o seu âmbito é restrito aos estados e municípios e distribuído de acordo com o número de alunos matriculados na rede pública de ensino. Constata-se que o novo fundo visa abranger a educação infantil e o ensino médio, deixando de fora as creches (GUILHERME; SALVADOR, 2013).

Abrahão (2005) ao comparar o financiamento e o gasto público voltados à educação básica no Brasil e de alguns países da OCDE e da América Latina mostra que nosso país se encontra em uma situação de aplicação de recursos bem abaixo da maioria dos países da OCDE e até mesmo dos principais países da América Latina. Nesse sentido, Amaral (2012) ressalta que as comparações internacionais mostram que os maiores desafios para o Brasil se encontram nas duas próximas décadas, quando da vigência dos dois próximos Planos Nacionais de Educação (PNEs).

A pesquisa realizada por Cara e Araújo (2011) sustenta que o custo apresentado pelo MEC no documento "Previsão de investimento necessário para cumprir o PNE, além do investimento atual de $5 \%$ do PIB", encaminhado em complementação ao projeto de lei ${ }^{9}$ pelo Ministério da Educação ao Congresso Nacional, não apresenta o real custo que se faz necessário para se cumprir o PNE com o necessário parâmetro de qualidade. O MEC apresenta um valor igual a 6,9\% do PIB, enquanto o referido estudo feito por Cara e Araújo (2011) aponta para a necessidade de um aporte $10,7 \%$ do PIB na educação.

Portanto, as três políticas sociais (assistência social, saúde e educação) aqui estudadas não apresentam uma evolução homogênea na repartição das responsabilidades entre a União e os entes da federação no tocante à gestão e ao financiamento dos seus gastos. O profundo ajuste fiscal em curso no Brasil desde o início século XXI, como resultado de políticas neoliberais da década de 1990, constitui um forte obstáculo para o avanço dos gastos sociais e a universalização das políticas públicas.

\footnotetext{
${ }^{9}$ Trata-se do projeto de lei que cria o Plano Nacional de Educação (PNE) para vigorar de 2011 a 2020 foi enviado pelo governo federal ao Congresso Nacional em 15 de dezembro de 2010. O novo PNE apresenta dez diretrizes objetivas e 20 metas, seguidas das estratégias específicas de concretização.
} 


\section{Financiamento das políticas sociais no contexto do ajuste fiscal}

Nos anos de políticas neoliberais no Brasil, uma das estratégias do ajuste fiscal, no âmbito das medidas econômicas do Plano Real foi a criação de mecanismos de desvinculação orçamentária com objetivos de realocação de recursos do fundo público livremente pelos condutores das políticas econômicas, sobretudo na esfera financeira (SALVADOR, 2010). Assim, em 1993, ocorreu no Brasil a criação do chamado "Fundo Social de Emergência" (FSE), permitindo a desvinculação de $20 \%$ das receitas arrecadadas pela União. O FSE foi substituído por um nome mais apropriado, nos exercícios financeiros de 1994 e 1995: Fundo de Estabilização Fiscal (FEF) e depois pela Desvinculação de Recursos da União (DRU), ainda em vigor. A DRU constitui um mecanismo importante de transferência de recursos tributários arrecadados em nome das políticas sociais que integram a seguridade social (previdência, assistência social, saúde e seguro-desemprego) para o orçamento fiscal, no entanto, tem um efeito perverso sobre o federalismo fiscal, pois as contribuições sociais que financiam essas políticas sociais não são partilhadas com os estados e municípios.

Com isso, a União após 1993 deu preferência na criação e na majoração de alíquotas tributárias das contribuições sociais em detrimento dos impostos que são partilhados com os entes federados. Em 1987, aproximadamente 64\% da receita pública disponível pertenciam à União; em 1991, a participação federal alcançava 53\% do total de recursos arrecadados nas três esferas de governo (PALOS, 2011), contudo, com o aumento da carga tributária não partilhada com o Distrito Federal, estados e municípios, a União centralizou, em 2011, 57\% do montante das receitas disponíveis em todas as esferas de governo (AFONSO; CASTRO, 2011).

Outra estratégia importante no ajuste fiscal brasileiro e que tem consequências diretas para as políticas sociais e as responsabilidades federativas é a chamada Lei de Responsabilidade Fiscal (LRF), a Lei Complementar no 101, de 4 de maio de 2000. Esta Lei foi responsável também pelo enquadramento dos estados e municípios aos objetivos da política fiscal do governo federal (SANTOS et al., 2003).

Desde 1992, o governo federal consolidou os seus créditos junto aos governos de estados e municípios, impondo prazos para pagamentos e limitando o endividamento, o que levou esses governos a financiar seus desequilíbrios orçamentários via bancos estaduais. Com os governos estaduais sem oportunidade de financiamento junto aos seus bancos públicos, ficou limitada a capacidade de expansão de investimentos dos orçamentos 
estaduais e de expansão dos gastos sociais locais. Santos et al. (2003) afirmam que o golpe de misericórdia para obrigar os estados e municípios a aderir ao ajuste fiscal federal foi a promulgação da LRF, impondo punição aos gestores que descumprissem a determinação legal de orçamento equilibrado. A privatização dos bancos estaduais, juntamente com a LRF, integrou os entes subnacionais ao "ajuste fiscal desejado a qualquer custo, pelo governo federal, como também foram determinantes paras que as metas de superávits orçamentários acordadas com o FMI fossem cumpridas" (SANTOS et al., 2003, p. 41).

Convém lembrar que as dívidas de estados e municípios foram renegociadas em 1997 e em 1998, beneficiando os detentores de títulos que estavam ameaçados de não serem honrados; as novas condições foram pactuadas em 2000. Um dos critérios acertados foi o comprometimento de $13 \%$ da receita com a dívida do refinanciamento feito pela União aos Estados e às grandes prefeituras. $\mathrm{O}$ art. 35 da LRF proíbe o financiamento de um ente da Federação a qualquer outro, incluindo a novação, refinanciamento ou postergação de dívida contraída anteriormente. Com isso, são "eternizadas" as condições estabelecidas nos empréstimos pactuados entre 1997 e junho de 2000 (MIRANDA, 2001). Para Lopreato (2006), a LFR mudou a lógica de conduta orçamentária de estados e municípios, significando elevados compromissos com o pagamento dos encargos financeiros e restrição de recursos fiscais disponíveis para outras despesas, assegurando, portanto, regras duras com o propósito de gerar superávits primários e garantir as condições de sustentabilidade da dívida pública.

A análise feita por Menezes e Júnior (2006) avalia os efeitos da LRF nas despesas dos municípios brasileiros, mostrando o aumento das despesas com juros e encargos da dívida. As despesas com investimentos tiveram acentuada diminuição em virtude da LRF, refletindo o ajuste promovido com queda expressiva na parcela da Receita Corrente Líquida (RCL) destinada ao investimento para a maioria dos municípios analisados pelos autores.

A LRF estabelece limites rígidos para gastos com pessoal subordinados a determinados percentuais da receita corrente de forma padronizada, sem considerar as realidades locais de estados e municípios de um país heterogêneo como o Brasil. A lei cria muitos constrangimentos para a gestão orçamentária, que aumenta o imobilismo e a lentidão do setor público, afetando a oferta e ampliação de serviços sociais, dificultando a realização dos investimentos e a geração de novas despesas de custeio, obrigando os entes subnacionais a priorizarem o cumprimento das metas de superávit primário (GARAGORRY, 
2007). Tudo isso, em um contexto de um federalismo que exige uma maior participação dos entes subnacionais no cofinanciamento das políticas sociais.

Soma-se às dificuldades dos governos subnacionais as possíveis perdas de receitas do FPE e do FPM, decorrentes das renúncias tributárias que a União vem concedendo ao setor industrial. A Receita Federal identifica o gasto tributário a partir das desonerações tributárias e também pela avaliação de quais desonerações são gastos indiretos e passíveis de substituição por gastos diretos. Trata-se de assunto pouco estudado, mas de elevado impacto orçamentário. De acordo com a Receita Federal (2011), os gastos tributários alcançaram o montante de $\mathrm{R} \$ 113,00$ bilhões no último ano, ou seja, 3,42\% do PIB.

Por fim, destaca-se a necessidade de um maior aprofundamento dos estudos sobre o financiamento das políticas sociais no contexto do federalismo brasileiro do século XXI, que esta inserido em uma lógica de sistema com a União regulamentando as finanças subnacionais no Brasil (ARRETCHE, 2012), indicando uma evolução heterogênea na repartição das responsabilidades entre os entes da federação, notadamente nas políticas de saúde, educação e assistência social. O federalismo não pode ser estudo de forma exógena, pois os entes que compõem a federação brasileira estão inseridos em ajuste fiscal estrutural, diminuindo a capacidade orçamentária tanto da União como dos estados, do DF e dos municípios para o financiamento das políticas sociais, em particular, àquelas de caráter universal, como a saúde e educação.

\section{Referências}

ABRAHÃO, Jorge. Estrutura de financiamento público da educação no Brasil. Brasília: IPEA, 2004.

Financiamento e gasto público da educação básica no Brasil e comparações com alguns países da OCDE e América Latina. Revista Educação e Sociedade, Campinas, v. 26, n. 92, p. 841-858, Especial - Out. 2005. Disponível em <http://www.cedes.unicamp.br>. Acesso em 12 de setembro de 2011.

AFFONSO, Rui. Descentralização e reforma do Estado: a Federação brasileira na encruzilhada. In Economia e Sociedade, Campinas, (14): 127-152, jun. 2000

AFONSO, José. CASTRO, Kleber. Carga Tributária Global no Brasil em 2010. São Paulo, set. de 2011. Disponível em: <http://www.joserobertoafonso.ecn.br>. Acesso em 15 abr. 2012.

ALMEIDA, Maria. Federalismo e políticas sociais. In: AFFONSO, Rui et al. Descentralização e políticas sociais. São Paulo: Fundap, 1996, p. 13-40. 
AMARAL, Nelson Cardoso. O novo PNE e o financiamento da educação no Brasil: os recursos como um percentual do PIB. Disponível em:

<www.cedes.unicamp.br/seminario3/nelson_amaral.pdf>. Acesso em: 04 fev. 2012.

ARRETCHE, Marta. Federalismo e políticas sociais no Brasil: problemas de coordenação e autonomia. São Paulo em Perspectiva, v. 18 (2), p. 17-26, 2004.

Federalismo e Igualdade Territorial: Uma Contradição em Termos? Dados

(Rio de Janeiro. Impresso), v. 53, p. 587-620, 2010.

2012.

Democracia, federalismo e centralização no Brasil. Rio de Janeiro: Editora FGV,

BEHRING, Elaine. Brasil em contra-reforma. São Paulo: Cortez, 2003.

Crise do capital, fundo público e valor. In: BOSCHETTI, Ivanete et al. (Org.).

Capitalismo em Crise, política social e direitos. São Paulo: Cortez, 2010.

BOSCHETTI, Ivanete; TEIXEIRA, Sandra; SALVADOR, Evilasio. Assistência social após 20 anos de LOAS: fim da travessia do deserto? In: SILVA, Marluce. Gerontologia: Saúde e previdência. Cuiabá: EdUFMT, 2013, p. 17-36.

CARA, Daniel. ARAÚJO, Luiz. O financiamento da educação no PNE II. In: MANHAS, Cleomar (Org.). Quanto custa universalizar o direito à educação. Brasília: INESC, 2011.

CASTRO, leda Maria Nobre de. Pacto Federativo e Financiamento da assistência social: as implicações da regulação do SUAS sobre os orçamentos municipais. Brasília, Revista Temporalis, ano 12, n.23, p.69-96, jan./jun. 2012.

CISLAGHI, Juliana Fiuza. Financiamento do ensino superior no Brasil: novos e antigos mecanismos de privatização do fundo público. In: SALVADOR, Evilasio et al. (Org.). Financeirização, fundo público e política social. São Paulo: Cortez, 2012, v. 1, p. 261-284.

CRUZ, Rosana. Federalismo e educação: um pacto a se rever. Revista Retratos da Escola, Brasília, v. 6, n. 10, p. 65-78, jan./jun. 2012.

DAIN, Sulamis. Financiamento público na perspectiva da política social. Revista Economia e Sociedade. Campinas, v. 17, p. 113-140, dez. 2001.

FREITAS, Nathalia. A materialização do SUAS no DF: o Estado garantido a primazia do setor privado. 2011. Dissertação (Mestrado em Política Social) - Universidade de Brasília, Brasília, 2011.

GARAGORRY, Jorge. Economia e política no processo de financeirização do Brasil (19802006). 2007. Tese (D outorado em Ciências Sociais) - Pontifícia Universidade Católica de São Paulo, São Paulo, 2007.

GEMARQUE, Rosana M. O. Políticas de Financiamento e Direito a Educação Básica: O Fundef e Fundeb. SER social, v. 13 n. 29, julho a dezembro de 2011. 
GUILHERME, Marcelo; SALVADOR, Evilasio. O financiamento público da política educacional no Distrito Federal no período de 2007-2010. In: YANNOULAS, Silvia Cristina. (Org.). Política educacional e pobreza: múltiplas abordagens para uma relação multi-determinada. Brasília: Liber Livros, 2013, v. 1, p. 128-145.

GUARDIA, Eduardo Refinetti. O processo orçamentário do governo federal: considerações sobre o novo arcabouço institucional e a experiência recente. In: IPEA/FUNDAP (Org.). Finanças Públicas: ensaios selecionados. São Paulo: Fundap, 1997.

IANNI, Octavio. Tendências do pensamento brasileiro. Tempo Social; Rev. Sociol. USP, S. Paulo, 12(2): 55-74, nov. 2000.

LEITE, Cristiane; FONSECA, Francisco. Federalismo e políticas sociais no Brasil: impasses da descentralização pós-1988. O \&S-Salvador, v.18, n.56, p. 99-117, jan./mar. 2011.

LOPREATO, Francisco. Política fiscal: mudanças e perspectivas. Política Econômica em Foco, n.7, p. 184-205, nov. 2005/abr. 2006.

MARTINS, Paulo. Fundeb, federalismo e regime de colaboração. Campinas: Autores Associados, 2011.

MDS. Política nacional de assistência social. Brasília: Ministério do Desenvolvimento Social e Combate à Fome, 2004.

. Norma operacional básica (NOB/SUAS). Brasília: Ministério do Desenvolvimento Social e Combate à Fome, 2005.

MELAMED, Clarice; PIOLA, Sérgio (Org.). Política Públicas e Financiamento Federal do Sistema Único de Saúde. Brasília: IPEA, 2011.

MENEZES, Rafael; JUNIOR, Rudinei. Regras fiscais no Brasil: a influência da LRF sobre as categorias de despesa dos municípios. Planejamento e Políticas públicas (IPEA), v. 29, p. 737, 2006.

MESQUISTA, Ana; MARTINS, Raquel de Fátima; CRUZ, Tânia. Cofinanciamento e responsabilidade federativa na política de assistência social. Brasília: IPEA, março de 2012. Texto para discussão n. 1.724 .

MIRANDA, Sergio. A verdadeira face da Lei de Responsabilidade Fiscal. Revista princípios, n. 61, julho de 2001.

MORONI, José. O direito à participação no governo Lula. In: FLEURY, Sonia; LOBATO, Lenaura. Participação, democracia e saúde. Rio de Janeiro: CEBES, 2009, p. 248-269.

OLIVEIRA, Fabrício. Economia e política das finanças públicas: uma abordagem crítica da teoria convencional, à luz da economia brasileira. São Paulo: Hucitec, 2009.

OLIVEIRA, Francisco de. A crise da Federação: da oligarquia à federação. In: AFFONSO, Rui de Britto Álvares; SILVA, Pedro Luiz Barros Silva (Org.). A federação em perspectiva: ensaios selecionados. São Paulo: Fundap, 1995. p. 77-90. 
Os direitos do antivalor: a economia política da hegemonia imperfeita. Petrópolis: Vozes, 1998.

PALOS, Aurélio. A Constituição de 1988 e o pacto federativo fiscal. Brasília: Câmara dos Deputados, março de 2011.

PISCITELLI, Roberto; TIMBÓ, Maria; ROSA, Maria. Contabilidade pública. 9. ed. São Paulo: Atlas, 2006.

PIOLA, Sérgio. VIANNA, Solon. Rompendo com as amarras no financiamento das políticas públicas de saúde. In: VAZ, Flavio. MUSSE, Juliano. SANTOS, Rodolfo. 20 anos de Constituição cidadã. Avaliação e desafio da seguridade social. Brasília: Anfip, 2008, p. 233-240.

PIOLA, Sérgio et al. Financiamento público da saúde: uma história à procura de rumo. Brasília: IPEA, julho de 2013. Texto para discussão n. 1.846.

POCHMANN, Marcio et al. (Org.). Os ricos no Brasil. São Paulo: Cortez, 2004.

PRADO, Sergio. Transferências fiscais no Brasil: o lado "esquecido" da reforma tributária. In: PINTO, Márcio. BIASOTO JR., Geraldo. Política fiscal e desenvolvimento no Brasil. Campinas: Editora da Unicamp, 2006, p. 173-236.

RIBEIRO, Thalita. O Sistema Único de Assistência Social (SUAS) no federalismo brasileiro do século XXI. 2013. Trabalho de Conclusão de Curso (Graduação em Serviço Social) Universidade de Brasília. Brasília, 2013.

SALVADOR, Evilasio. Fundo Público e Seguridade Social. São Paulo: Cortez, 2010.

Orçamento da assistência social entre benefícios e serviços. In: VAZ, Flávio Tonelli; MARTINS, Floriano José (Org.). Orçamento e Políticas públicas: condicionantes e externalidades. Brasília: ANFIP, 2011, p. 199-222.

. Financiamento tributário da política social no pós-real. In: SALVADOR, Evilasio et al. (Org.). Financerização, fundo público e política social. São Paulo: Cortez Editora, 2012a, p. 123-152.

. Fundo Público e Financiamento das Políticas Sociais no Brasil. Serviço Social em Revista (Online), v. 14, p. 4-22, 2012 b.

As Implicações do Sistema Tributário Brasileiro nas Desigualdades de Renda. Brasília: INESC, 2014.

.; TEIXEIRA, Sandra. Orçamento e políticas sociais: metodologia de análise na perspectiva crítica. Revista de Políticas Públicas (UFMA), v.18, n. 1, janeiro a junho de 2014. SANTOS, Reginaldo et al. Economia política e finanças públicas no Brasil: a recuperação de um debate. Bahia análise e dados, Salvador, v. 12, n. 4, p. 25-43, mar. /2003. 
STN. Balanço do Setor Público Nacional. Brasília: Secretaria do Tesouro Nacional, 2013. Disponível em: <https://www.tesouro.fazenda.gov.br/pt/contabilidade-publica/principaispublicacoes/relatórios>. Acesso em: 2 de abril de 2014.

SOUZA, Celina. Federalismo, desenho constitucional e instituições federativas no Brasil pós1988. Revista Sociologia Política, Curitiba, 24, p. 105-121, jun. 2005.

WIZIACK, Julio. Brasil já possui 220 mil milionários, diz pesquisa. Folha de São Paulo, 05/09/2008. Disponível em:

<http://www1.folha.uol.com.br/folha/dinheiro/ult91u441681.shtml>. Acesso em: 2 de abril de 2014. 